\title{
Discours
}

Revue de linguistique, psycholinguistique et

informatique. A journal of linguistics, psycholinguistics and computational linguistics

$27 \mid 2020$

Varia

\section{The Prominence Value of the Temporal Anchor of Free Indirect Discourse: A Comparison with the Perspectival Center}

Jakob Egetenmeyer

\section{OpenEdition \\ Journals}

Electronic version

URL: http://journals.openedition.org/discours/11101

DOI: $10.4000 /$ discours. 11101

ISSN: 1963-1723

\section{Publisher:}

Laboratoire LATTICE, Presses universitaires de Caen

\section{Electronic reference}

Jakob Egetenmeyer, "The Prominence Value of the Temporal Anchor of Free Indirect Discourse: A Comparison with the Perspectival Center", Discours [Online], 27 | 2020, Online since 23 December 2020, connection on 13 April 2021. URL: http://journals.openedition.org/discours/11101 ; DOI: https:// doi.org/10.4000/discours. 11101 

Revue de linguistique, psycholinguistique et informatique

\section{The Prominence Value of the Temporal Anchor of Free Indirect Discourse: A Comparison with the Perspectival Center}

Jakob Egetenmeyer

University of Cologne 



\title{
The Prominence Value of the Temporal Anchor of Free Indirect Discourse: A Comparison with the Perspectival Center
}

\author{
Jakob Egetenmeyer
}

University of Cologne

Free indirect discourse (FID) is a kind of speech or thought representation that lacks specific marking. The entity to whom the speech or thought is attributed (the perspectival center) has been shown to be a contextually available prominent protagonist (see Hinterwimmer, 2019). A shortcoming of the literature is that it ignores the problem of the temporal anchoring of FID events. The present article is dedicated to such anchors. It focuses on their prominence value and discusses their relevant properties. It shows that FID has a strong tendency to be temporally anchored to a prominent time point. Thus, the protagonist and the anchor time point share the trait of prominence.

Keywords: free indirect discourse, temporal anchoring, prominence, temporal relations, temporal discourse structure, comparison of times and individuals

This research was funded by the Deutsche Forschungsgemeinschaft (DFG - German Research Foundation) as part of the Collaborative Research Center 1252 "Prominence in Language", Project-ID 281511265, which is gratefully acknowledged. An earlier version was presented as a poster at the SFB 1252 New Year's Meeting in January 2019. We are grateful to the audience for their feedback. We thank Robert Tegethoff for proofreading an earlier draft, Mary Chambers for proofreading the final draft, and Barbara Zeyer and David Wick for practical assistance. We also thank Stefan Hinterwimmer for pointing out to us interesting FID examples in H. Mann (1918) and T. Mann (1963), of which we cite two in the present contribution. Finally, we are particularly grateful for the very helpful input from three anonymous reviewers.

\section{Introduction}

Free indirect discourse (FID) is a literary phenomenon in which the speech or thought of a character is expressed without explicit lexical indications for the quote (see Lips, 1926; Banfield, 1982; Eckardt, 2014; etc.). However, readers are still easily able to recognize that it is not the narrator who is responsible for the content of the FID and, as Hinterwimmer (2019) shows, they generally know to which character within the story the referred content needs to be attributed ${ }^{1}$. This is due to the special use of deictics, evaluative expressions and other indicators (see Section 2) ${ }^{2}$. Interestingly, FID has been shown to feature a specific mix of indications which partly favor the narrator and partly a character as the speaking entity (see e.g., Maier, 2015), which

1. An instance of FID is almost always attributed to a character different from the narrator. However, as Eckardt (2014: 51) shows, the perspective taker may in exceptional cases coincide with the narrator.

2. While these elements may be taken as indicators, they also need to be processed. As Köder et al. (2015: 944) show, a "perspective shift [...] increases the processing effort of pronouns". 
is an important property distinguishing it from other forms of speech or thought representation. This constellation leads to the description, prevalent in the recent research literature, that there are two voices or contexts available which overlap in FID (see Doron, 1991; Schlenker, 2004; Eckardt, 2014; etc.).

The resolution of FID to a character in the story is unproblematic when there is only one character available. However, when there is more than one protagonist, the resolution may be less evident. This question has only recently been approached by Hinterwimmer (2019), who shows that a disambiguation is possible and that it is always the most prominent protagonist in the context who functions as the perspectival center, i.e., to whom the FID is attributed. In example [1], Bob is the perspectival center. The FID consists of the second and third sentences.

[1] Bob welcomed Anna with excitement. He had found her car key! Wasn't she lucky to bave him?

(Eckardt, 2014: 1, adapted)

In terms of the temporal characteristics of FID, the focus of the research literature is unbalanced. First, much of the literature considers tense choice (see Banfield, 1982: 104; Landeweerd \& Vet, 1996; Reboul et al., 2016; etc.). Second, from a discourse perspective, temporal relations are of central interest but they have not yet received much attention (see Egetenmeyer, accepted a). Bu (2016) and, to a minor extent, Lo Cascio (2002) may be considered exceptions. Third, when the subject of temporal relations is mentioned, there is a strong tendency towards the overgeneralization of co-temporality relative to the preceding discourse. However, Egetenmeyer (accepted a) shows that a variety of temporal relations between FID events and the surrounding context is possible. A FID event is basically defined as the uttering event of an instance of FID (see Egetenmeyer, accepted a; Section 2.2 below presents further details). Finally, temporal anchoring is largely ignored in the literature (see Ehrlich, 1990: $74 \mathrm{ff}$. for an exception), even though it is a basic component of temporal relations. What is more, on the rare occasions when the relationship is mentioned, it is analyzed only with respect to an explicit verb of speech or thought (e.g. Bu, 2016), which may be realized parenthetically (see Banfield, 1982: 76). It may then parallel what we find in indirect discourse. However, cases which lack such an explicit parenthetical verb are conceptually much more interesting. As the (preceding) context may contain a potentially infinite number of time points available as candidates for anchoring, the problem is to identify which time point functions as the temporal anchor of the FID event. An important factor that reduces the number of possibilities is recency. More specifically, we may suspect that the anchor time is introduced in the sentence directly preceding the FID. However, this is not always the case, and thus recency cannot be the only relevant factor. As we will see in Section 3.2, it may be overruled. Still, as temporal relations do not seem to pose special problems to readers, we may suspect that there are well entrenched mechanisms that allow the reader to retrieve the anchor time. To understand the problem better, we therefore need to consider its structurally relevant properties. 
In sum, we seek to answer the following questions: (i) which preceding time point functions as the anchor of FID events, (ii) what properties does it have, and (iii) do these properties parallel those of the perspectival center? The hypotheses are that a FID event is anchored to a prominent time point introduced via the preceding discourse and that it thus parallels the perspectival center.

In Section 2, we introduce the relevant properties of FID as discussed in the literature and indicate how it is delimited from other forms of speech or thought representation and perspective shift. Section 2.1 focuses on the analysis by Hinterwimmer (2019) concerning the perspectival center. This is relevant in order to show that certain properties of temporal reference parallel those of the domain of reference to individuals. Section 2.2 concentrates on the temporal relations of FID events as described in Egetenmeyer (accepted a). Section 2.3 narrows down the aim of this paper more precisely. In Section 3, we then lay out our account of the prominence value of the anchor time point and determine the relevant factors (Section 3.1). We also discuss the problem of competing time points (Section 3.2). Section 4 presents a detailed analysis of a specific set of FID instances with respect to three main categories. In the conclusion (Section 5), we compare the prominence properties of the anchor time point with those of the perspectival center.

\section{Free indirect discourse (FID)}

According to a basic definition (see also Section 1), FID is a special kind of speech or thought representation which lacks an introductory declarative verb but still expresses the conscious state of mind of a protagonist within the story (see e.g., Eckardt, 2014 for FID; and Hinterwimmer, 2017 for a distinction of FID from other forms of perspective shift; see below). In simplified terms we can state that its internal form shares characteristics both with direct and indirect discourse, while its syntactic status parallels that of direct discourse. The FID sentence or passage is not embedded under a speech verb, even though "it may (but need not) be accompanied by a parenthetical clause" (Banfield, 1982: 76), which may be positioned after (see example [2]) or within the FID sentence (see Banfield, 1982: 76).

[2] What message could Cam give the cook? Mrs Ramsay wondered.

(Woolf, To the Lighthouse, 1974: 88; taken from Banfield, 1982: 76) ${ }^{3}$

Superficially, example [2] seems to parallel what is generally assumed for indirect discourse (cf., however, Hunter, 2016; see Section 3.2). Simply put, all relevant discursive properties might be attributed to the parenthetical structure. In the case of [2], this yields a correct interpretation insofar as the content of the FID is to be attributed to the explicitly mentioned character (Mrs Ramsay) and the

3. Banfield (1982: 76) leaves out the question mark, putting a comma in its place. In the original as we quote it, the clause expressing the wondering might be interpreted as a proper sentence of its own. 
temporal location of the parenthetical verb is also indicative of the FID's temporal location in discourse. However, on the one hand, FID not only shows properties of indirect speech, but combines them with characteristics of direct speech (see Sharvit, 2008: 354; Maier, 2017: 261). On the other hand, as it does not always feature a parenthetical verb, we cannot base an analysis of FID on such a verb. Before we come back to the problem of the temporal localization of FID without parenthetical verbs, we need to take a look at the central properties of FID and how the literature accounts for them. Furthermore, we will show how FID can be distinguished from competing phenomena.

The deictic expressions contained in FID passages differ with respect to the source of information to which they are attributed, either the narrator or a character within the story. In the recent literature, this is mostly analyzed as a distinction between two voices (see Doron, 1991) or between two contexts, in the sense of Kaplan (1989) (see Schlenker, 2004; Eckardt, 2014; etc.), which overlap in the case of FID. This can be shown nicely with our example from Section 1, which is repeated below with a further adaption ${ }^{4}$.

[3] Bob welcomed Anna with excitement. He had just found her car key! Wasn't she lucky to have bim?

(Eckardt, 2014: 1, adapted)

The FID passage in the example contains third person pronouns, rather than first and second person pronouns as it would in direct speech. In the example, the realization of the personal pronouns parallels indirect speech: they are chosen according to the narrator's context, that is, the external context with respect to the FID (see Eckardt, 2014: 30). As Bu (2016) underlines, the temporal reference is typically also set relative to the reference time of the non-FID story line (see further below). By contrast, as listed by Hinterwimmer (2019: $80 \mathrm{f}$.), $1^{\text {st }} / 2^{\text {nd }}$ person pronouns, temporal adverbials (like just in the example) ${ }^{5}$, evaluatives and expressives are attributed to the protagonist's context. This also includes the illocutionary force of a clause. In the example, the exclamation and the question are attributed to the protagonist (see e.g., Eckardt, 2014: 9 f. for these properties and further indications of FID). Finally, as the discussion of tense in Landeweerd and Vet (1996) indicates, tense choice in FID is language-dependent. For example, while English uses the simple past, the Romance languages opt for imperfective tense-aspect forms (see Banfield, 1982: 104). Therefore, tense cannot receive a general attribution to one context or the other (see also Giorgi, 2015: 238).

4. We added the adverb just.

5. A very interesting contribution with respect to adverbials is that of Anderson (2019). On the evidence of a set of experiments, she argues that the adverb tomorrow shows two different anchoring possibilities. According to her, it is either anchored to the utterance time or "to a non-[utterance time] perspective" (Anderson, 2019: 53) if this perspective is salient. 
Its specific properties allow for FID to be singled out with respect to competing phenomena within two realms. The first one is the representation of speech and thought. The second one is perspective shifts. We have mentioned many properties already; however, we have not yet categorized them properly.

On the one hand, FID needs to be distinguished from other forms of speech or thought representation. Relevant indicators can be found on all linguistic levels. First, there are syntactic and morphosyntactic properties which FID only partially shares with other forms of speech and thought representation. Like direct speech it is not syntactically subordinated, but, like indirect speech (which shows syntactic subordination, however), "tenses and pronouns are shifted" (Vetters, 1994: 179, with reference to Lips, 1926: 51). Above, we mentioned the specific tense choice found in the Romance languages. This parallels indirect speech (Maier, 2015: 368, footnote 39). Second, FID shares lexical and semantic properties with direct speech, insofar as the protagonist may express evaluations which are only mediated by the narrator; the style and expressions of the protagonist may also be used (see Eckardt, 2014: 9). Third, with regard to pragmatics, temporal and local deictic expressions parallel the realization of direct discourse (see Hinterwimmer, 2019: $80 \mathrm{f}$.). Finally, despite the predominant use of FID in the written medium, Maier (2015: $349 \mathrm{f}$.) even presents evidence for phonological and prosodical indicators which parallel direct discourse, as dialects may be represented in FID.

On the other hand, FID is a specific kind of a shifted perspective and therefore also needs to be differentiated from other perspective shifting phenomena. The unifying property of this group is that a piece of information is not presented from the point of view of the narrator but from that of a protagonist ${ }^{6}$. The most important competing subtype is called viewpoint shift by Hinterwimmer (2017) and protagonist projection by Abrusán (2020), who follows Holton (1997). Hinterwimmer (2017: $283 \mathrm{f}$., 291) lists three properties which distinguish FID from viewpoint shift: (i) only FID features a context shift, (ii) FID is always a conscious speech or thought of the protagonist, while viewpoint shift may be unconscious, and (iii) FID only occurs at the root level, while viewpoint shift is also possible sentence-internally ${ }^{7}$.

Importantly, the lists of properties of the two realms of phenomena may be further extended and deepened. Especially with respect to other forms of speech or thought representation, the research literature is very rich and its history spans several decades. By contrast, the research on viewpoint shifting phenomena is

6. The perspective may also be shifted in the other direction, that is, from a protagonist to the narrator (see Hinterwimmer, 2018; Becker et al., accepted).

7. An example of viewpoint shift presented in Hinterwimmer (2017) is [i]:

[i] When Mary stepped out of the boat, the ground was shaking beneath her feet for a couple of seconds. (Hinterwimmer, 2017: 291)

As Hinterwimmer (2017: 291) underlines, the adverbial clause makes reference to a fact in the narrated world, while the second clause expresses a (possibly unconscious) sensation of Mary, as a real shaking event is not necessarily the case in the narrated world. 
relatively recent. Both discussions continue to be lively. As said, the distinctions themselves are not the focus of our study, although the insights we present here may and should be integrated into the more general research. Therefore, we will not go into further detail. However, we still need to determine the categories involved in the description of the temporal relations of FID.

The reference time mentioned above is a crucial concept in the analysis of temporal discourse structure and especially in the description of narrative texts. It is the point in time to which a narrative has developed when a certain event occurs (see Kamp et al., 2011: 199). It is central when it comes to determining temporal anchoring because, within a story, the location time of an event is anchored to a preceding reference time (see Kamp \& Rohrer, 1983; and Becker \& Egetenmeyer, 2018a, for formal specifics). It is also relevant for FID events which form part of temporal discourse structure. When a parenthetical verb co-occurs with an instance of FID, this verb contributes the reference time. In cases where a parenthetical verb is lacking, the FID event itself contributes the reference time (see Egetenmeyer, accepted a). This is discussed in depth in Section 2.2. However, we can already emphasize that upon this conception, the FID event can be temporally localized in a narrative in a specific way. Furthermore, the account does not involve an overly extensive terminology. The localization is determined on the grounds of concepts coming from Discourse Representation Theory (DRT) (see e.g., Kamp et al., 2011). An alternative might be, for instance, the assessment time as put forth in Anand and Toosarvandani $(2018 \mathrm{a} \text { and } \mathrm{b})^{8}$.

\subsection{The perspectival center (Hinterwimmer, 2019)}

As we have seen, usually a narrator and a protagonist context are distinguished in FID. Now, when the story contains more than one protagonist, the FID content may in principle be attributed to any of them. Hinterwimmer (2019) analyzes which character gets to be chosen as the one to utter or think in cases of FID. He determines the properties leading to a ranking between the available characters and shows that it is the highest-ranking character, i.e., the most prominent one, to whom the FID is attributed, that is, who becomes the perspectival center. In fact, as Hinterwimmer (2019: 81) states, being prominent is a prerequisite for being a perspectival center. He shows that two groups of prominence properties are relevant, namely, local and global ones. The following quote neatly sums this up:

$[\mathrm{O}]$ nly those discourse referents are available as perspectival centers that meet one of the two following conditions: They are either maximally prominent in terms of grammatical function and thematic role/agentivity features in the sentence

8. The "assessment time" presented in Anand and Toosarvandani (2018b) can be understood as the time about which we speak when we speak about an event or a set of events. It shares characteristics with the reference time (in the sense of Kamp \& Reyle, 1993: 523 ff., and others) and the topic time discussed by Klein (1994). Contrasting the other two concepts, the assessment time may include more than one eventuality (see Anand \& Toosarvandani, 2018b: 82). 
immediately preceding the one in FID mode or they are globally prominent with respect to the entire text segment containing that sentence.

(Hinterwimmer, 2019: 86)

Thus, the relevant local prominence properties concern the status of the expression referring to the perspectival center in the preceding clause. Generally, in nominative-accusative languages, the subject role is understood as being the part of speech yielding the highest prominence value (see Hopper \& Thompson, 1980; Aissen, 2003; Næss, 2007; etc.). It often correlates with thematic role features that also contribute to a high prominence value, such as agentivity and sentience (see Dowty, 1991; Primus, 2006; etc.). With regard to the global or macro-level prominence value, Hinterwimmer (2019: $87 \mathrm{ff}$.) shows that the relevant property is that the protagonist is a non-local discourse topic.

To substantiate his claims, Hinterwimmer (2019) presents a set of examples where he modifies certain characteristics. One of them is cited below (see Hinterwimmer, 2019: 85). We introduce a partitioning to make the discussion easier.

[4.i] George entered the room and looked around cautiously. Susan was sitting at a table in the corner with her best friend.

[4.ii] Susan looked at George hatefully.

[4.iii.a] The dumb jerk bad managed to make her look like an idiot at the meeting yesterday.

[4.iii.b] The mean old hag had managed to make him look like an idiot at the meeting yesterday.

(Hinterwimmer, 2019: 85)

To have a closer look at local prominence properties, we need to ignore [4.i] for the moment and consider [4.ii] as the beginning of our text segment. The incompatibility which surfaces supports the role of the local prominence value. Hinterwimmer (2019: 84) argues that the sentence may plausibly only be followed by [4.iii.a] as only Susan is available as a perspectival center. This is so because in [4.ii], the noun phrase Susan appears as the subject and the denoted entity may be interpreted as the agent of a viewing event, i.e., "the proper name Susan is more prominent than George" (Hinterwimmer, 2019: 84).

The picture changes if we also take [4.i] into account. In these two sentences, George is introduced as a discourse topic, and therefore becomes an alternative perspectival center for the FID (see Hinterwimmer, 2019: 85). In the way the example is presented, George is actually the more probable perspectival center (Hinterwimmer, 2019: 89) ${ }^{9}$. This underlines the role of the global prominence value.

9. Hinterwimmer (2019: $87 \mathrm{ff}$.) tests and further substantiates this claim by inverting the first two sentences, which again makes Susan the more probable perspectival center. 


\subsection{The FID event and temporal anchoring (Egetenmeyer, accepted a)}

A thorough analysis of the temporal relations in passages containing FID requires a further distinction we only applied implicitly above, namely that the FID content needs to be distinguished from the FID event (see Egetenmeyer, accepted a). So far, the research literature has generally focused on the FID content. However, this entails a restrictive view which in fact inhibits our understanding of the temporal discourse structure. Egetenmeyer (accepted a) shows that the FID event is decisive in this respect and that the temporal relations between FID and the surrounding context are much more varied than is generally acknowledged in the literature. In the following, an overview of this account is provided; for more in depth considerations the reader is referred to the original paper.

The FID content is the propositional content of what is understood as being uttered by the perspectival center. Temporally, it is only indirectly connected to the surrounding discourse. By contrast, the FID event is a discourse entity which is a proper part of the discourse passage it occurs in. It maintains specific temporal relations to the surrounding co(n)text. We can show this distinction with resumptive pronouns. In [5.i], we repeat the example from Section 2. The second and third sentences are FID. Interestingly, [5.i] may be followed by [5.ii.a], but alternatively also by [5.ii.b].

[5.i] Bob welcomed Anna with excitement. He had just found her car key! Wasn't she lucky to bave him?

(Eckardt, 2014: 1, adapted)

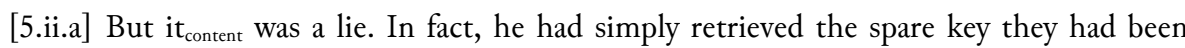
keeping in the drawer.

[5.ii.b] $\mathrm{It}_{\text {event }}$ was only a short announcement as he quickly rushed back to the TV set.

In both continuations, the pronoun it is used resumptively. However, in [5.ii.a], the pronoun refers back to the content of the FID which precedes it, whereas in [5.ii.b], it makes reference to the free indirect speech act itself, i.e., the FID event (see Egetenmeyer, accepted a, for a further example).

As said, the FID event is a discourse entity. Therefore it also has a temporal extension. This can be shown with the following sentence, which is a third possible way of continuing the fragment of [5.i].

[5.ii.c] Then he gave it back to her.

As the adverbial then in [5.ii.c] indicates, the FID event may also be referred to temporally. Thus, it is part of the discourse dynamics. Due to its property of being a discourse entity, the time point introduced via the FID event receives a certain prominence value. Therefore, we will also compare it to the value of the anchor time (see Section 4.1). With this as background, we can now discuss the possible temporal relations between the FID event and the surrounding context. 
As said, tense choice in FID is language-specific (see Landeweerd \& Vet, 1996). For example, while English allows for the use of the simple past, the direct equivalent is uncommon in the Romance languages (passé simple in French, préterito indefinido in Spanish, etc.), which, by contrast, prefer imperfective tense-aspect forms (e.g., the French imparfait or the Spanish imperfecto) (see Banfield, 1982: 104). The possibilities concerning the temporal relations are, by contrast, expected to be generalizable (see e.g., Bu, 2016, for a recent account concerning English). Here, we restrict our focus to the relationship between FID events and their preceding contexts. Egetenmeyer (accepted a) additionally discusses the relationship of FID to the following context and the temporal development within FID.

The FID event is anchored to a time point which is usually provided in the preceding context. There are three main temporal relations: inclusion, sequence and (overlapping) precedence, exemplified in [6], [7] and [8], respectively.

[6] Bob was sitting next to Anna. How she bad looked at him!

(Eckardt, 2014: 48, adapted)

[7] Bob opened the window. What a lovely afternoon!

(Eckardt, 2014: 99, adapted)

[8] Tom shuddered. The ghost in the attic was making noises again.

(Eckardt, 2014: 60, adapted)

The first sentence in [6] introduces a reference time within which the thought is realized. Without further context, this is a case of an inclusion relation. Here we see a clear difference between the temporal location of the FID event and the FID content. As the pluperfect form underlines, the looking event referred to by means of the FID (the FID content) occurs before the FID event. In [7], the FID event is realized after the event of opening the window. In contrast to Eckardt (2014: 99), Egetenmeyer (accepted a) argues that an intervening eventuality is also probable, namely, a perception event which then leads to the expression of the emotional reaction. In [8], by contrast, the FID expresses the thought which leads to the reaction expressed in the first sentence (an EXPLANATION relation in the sense of Asher \& Lascarides, 2003). Therefore, the FID event has to be temporally located before the event of the first sentence, even though partial temporal overlap is possible.

In the discussion of these short examples, we go beyond the current research literature with respect to temporal relations. Still, an important possible problem has not yet surfaced, namely, the case of alternative temporal anchors. The following two construed examples feature more than one possible anchor time. This phenomenon is not discussed in Egetenmeyer (accepted a).

[9] At midnight, John went for a walk. Then he went to bed. Ob my, it was so dark at midnight! 
[10] John cleaned the kitchen. He had prepared a cake. The next day, his friends would come over. Awesome! The perfect party!

[11] John cleaned the kitchen. Before that he had prepared a cake. Awesome! The perfect cake!

What we see in [9] is that, even though the FID content concerns the time of the walk and takes it up explicitly (at midnigbt), the FID event is still realized at the time point introduced in the second sentence (went to bed). The preferred reading is a generalizing statement in the light of the protagonist's specific experience. By contrast, if a pluperfect form (bad been [so dark]) is used instead of the simple past (was) the reading is rendered specific. The assertion can then only concern the time of the protagonist's walk. Importantly, the temporal anchoring to the reference time introduced in the second sentence does not change. Thus, temporal anchoring is not easy to manipulate ${ }^{10}$.

The FID in [10] and [11] lacks an explicit verb which allows us to test the effect of the verb on the flexibility of the anchoring. Interestingly, the most probable reading of [10] is that the FID expresses John's excited anticipation. More specifically, the main perspective time equals the reference time introduced as part of the first sentence $\left(R_{I}\right)$. The second sentence presents a flashback. The third sentence maintains the perspective time, but with a forward-looking perspective. The same holds true for the FID. It is temporally anchored to $R_{1}$. The example is altered in [11]. We might expect that adapting John's exclamation in such a way as to concern the quality of the cake would lead to an anchoring to the second sentence. However, this is not the case. The dominant reading is, rather, that John reflects on his cake while cleaning.

Importantly, in these examples, the temporal anchoring cannot be directly deduced from a verb of speech or thought. Thus, they cannot be treated in the same way as indirect discourse. However, as an anonymous reviewer correctly pointed out, the temporal anchoring parallels the functioning of temporal anaphora in nonFID contexts (see especially example [10]). Therefore, even though their different conceptual status may be considered a weighty argument in favor of this treatment, it is important to show that anchoring in FID contexts may indeed diverge from other, parallel contexts. The following example pair shows this.

[12.a] John cleaned the kitchen. Before that he had prepared a cake. Wow! The perfect cake, but such a mess in the kitchen!

[12.b] John cleaned the kitchen. Before that he had prepared a cake. He thought that the cake looked delicious but the kitchen needed to be cleaned immediately.

10. Concerning another example, an anonymous reviewer suggested considering the role of the place variable. This is also relevant here. While the FID content may concern the place implied in the first sentence ("outside John's home"), the FID event is realized at the place introduced in the second sentence ("in John's bed”). 
[12.a] and [12.b] present approximately the same content. However, they diverge with respect to the form of speech and thought representation. [12.a] contains an instance of FID without an explicit speech or thought verb. By contrast, [12.b] features indirect speech involving a verb of thinking (thought), which allows for a direct anchoring. Both examples are linguistically felicitous. Interestingly, they yield different temporal structures. While, in [12.a], the dominant reading is again that the FID is realized at the time of the cleaning event, in [12.b], the thinking is rather anchored to the second event or its post-state, i.e., the time at which the cake is finished. As we see, a temporally explicit verb form is not necessary (bad thought). This divergence leads us to the central question of the paper at hand. Which qualities license a time point as anchor time for FID? We hypothesize that it has to be a prominent time point. In [12.a], the FID event is most probably anchored to the highest-ranking time point, which functions as the perspective time of the flashback in the second sentence. In [12.b], by contrast, a structural recency effect leads to an anchoring to the pre-past time point introduced in the second sentence. In Section 3, we determine what makes a time point prominent.

\subsection{Delimiting the scope of the present paper}

In the preceding sub-sections, we presented the problem of the temporal anchor of FID and underlined its relevance. We showed the deficiency of the research literature, which hardly even mentions the problem. However, as we touched upon very different strands of discussions, we want to conclude this section with a brief summary of the scope of the present paper. Furthermore, we seek to delimit it from two of our other papers which also concern FID (Egetenmeyer, accepted a; Egetenmeyer, submitted a).

We begin with two restrictions, but we will also indicate the way in which the present paper helps to solve the respective problems. The contribution at hand does not focus on the question of how to determine instances of FID. Furthermore, it does not add new insights on how to determine the character to whom the FID content is attributed. However, it does contribute to the understanding and characterization of the two problems. Firstly, its main aim is to present new insights into the functioning of FID. More specifically, it seeks to determine the quality of the anchor time of FID events. This property is central when it comes to describing FID as part of the discourse in terms of temporal structuring. Thus, this is also relevant for a general characterization of FID. Secondly, we not only describe the prominence value of the anchor time with respect to other time points in the surrounding context, but we also seek to compare this property with the characteristics of the perspectival center, that is, the character who utters the FID. Thus, by comparing the prominence values of the two different types of entities (times and individuals), the account can also deepen our understanding of the quality of the perspectival center.

We have contrasted the present account with many other publications. However, it has not yet been properly set apart from two of our papers which also deal with FID. Egetenmeyer (accepted a) focuses on the temporal relations relevant in contexts involving FID in a general perspective. The paper introduces the distinction 
between the FID content and the FID event and determines the FID event as a discourse entity. It discusses the possible temporal relations of the FID event with respect to the preceding and the following discourse and also the temporal development within (longer) FID events. All three types of relationships may be instantiated as precedence, co-temporality or sequence (with subtypes involving or not involving overlap, partial or perfect co-temporality, etc.). In contrast, this paper focuses on an important property of the temporal relationship of the FID event with the preceding discourse, namely, the temporal anchoring. It determines the temporal anchor and discusses its characteristics. It shows that the temporal anchor is a time point with an elevated prominence value. It follows Hinterwimmer (2019) in considering a sentence-based local level and a macro-level (beyond the single sentence). In addition, it considers the rhetorical relations involved, which are also taken into consideration in Egetenmeyer (accepted a). In order to properly develop its specific interest, this paper presents a thorough description of the indicators of the prominence value of time points (see Section 3.1 and the data analysis in Section 4). The discussion of how to determine the anchor time is also a new contribution to the scientific research on FID (see Section 3.2).

Egetenmeyer (submitted a) is based on the insights from the present study. Specifically, it tests one of the findings of the present paper experimentally, namely, the prominence properties of the local level. To be able to do so, it goes beyond the scope of the present paper, refining some of the relevant insights in order to operationalize them, by using a forced-choice task. In contrast to the present paper, which is not entirely restricted to French, the experiment in Egetenmeyer (submitted a) only considers French data. The experimental results not only confirm that the findings of the present paper are correct but also indicate that they are relevant for speakers/hearers when they are confronted with instances of FID.

\section{The prominence value of the anchor time point}

The free indirect speech or thought act (i.e., the FID event) has to occur at a certain point in time. We assume that, usually, the FID event is not intended to be virtual or generic or otherwise temporally detached from the context ${ }^{11}$. Thus, the time point at which it is realized is expected to be specific. Due to the coherence requirements of a text, this time point cannot be just any time, but has to be one that is available in the preceding context. However, the preceding context may be extended and, in principle, an unlimited number of time points are possible candidates. For the selection of a time point as a temporal anchor for a FID event, the relevant time point should have specific characteristics. We hypothesize that it is one with a relatively high prominence value as compared to surrounding time points.

11. However, habituality may sometimes be found in the preceding context. It might be worth investigating its role more thoroughly. We cannot go into detail here (see, however, the discussion of the last example in Section 4.2). 
For the definition of prominence, we adhere to Himmelmann and Primus (2015: 38, 42, $44 \mathrm{f}$.) and the precisions presented in Becker and Egetenmeyer (2018a: $45 \mathrm{ff}$.). Prominence is defined as a relational property of an element as part of a specific domain which holds relative to other elements of the same type and pertaining to the same domain. A prominent element stands out within the set of equal elements in its domain. Thereby, it becomes an "attentional center [...]" and may "serve as anchor [...] around which experience is organi[z] ed" (Himmelmann \& Primus, 2015: 42, 44). This property is highly important in temporal discourse structure where the prominence values of time points and intervals prove to be a central structural determinant. For temporal structuring, the relevant domain is a semantically determined coherent text segment, e.g., an episode (see Becker \& Egetenmeyer, 2018a: $45 \mathrm{ff}$. for a formalization).

Importantly, time points may be compared in terms of the prominence value they have (see below and, more specifically, Section 3.1). In the literature on temporal discourse structure, different types of time points are considered. In this analysis, we focus on two types, namely, reference times and location times (in the sense of, e.g., Kamp \& Reyle, 1993; Kamp et al., 2011). Prominence is a gradient property. Four different values of time points have been shown to be relevant for temporal discourse structure (see Becker \& Egetenmeyer, 2018a; Egetenmeyer, 2020): maximal prominence within a domain, an elevated prominence value, equal prominence and minimal or low prominence. A maximally prominent time point is the most important attractor in the domain it occurs in, which may be the case, e.g., for the first time point of an episode (see Becker \& Egetenmeyer, 2018a: $47 \mathrm{ff}$.). A time point with an elevated prominence value diverges from surrounding time points due to certain features, e.g., precision or explicitness, which make it stand out. Equally prominent time points are, for instance, reference times introduced via certain events as part of a narration in sequence. Their prominence value is then set by default (see Becker \& Egetenmeyer, 2018a: 49), thus leveling out minor prominence distinctions which do not influence temporal discourse structure. Finally, minimally prominent time points are not available as anchors (see Egetenmeyer, 2020).

The research literature hardly considers the role of FID within discourse structure. What is more, the prominence value of the anchor time of FID events does not seem to have been treated yet. However, in a different context, namely concerning the adverb now, Altshuler (2010) presents a relevant insight. He states that "now supplies [...] the time of an event $\mathrm{e}_{\mathrm{m}}$ that requires a salient antecedent ([...] perspectival event)" (Altshuler, 2010: 252 f.). On similar lines, Anderson (2019: 53) presents evidence "that tomorrow takes the time parameter of a salient perspective as its reference time". As we will see, this is paralleled in FID.

In the following Section 3.1, we introduce properties that mark a time point as prominent. We also propose a basic classification of these properties, which parallels the one presented in Hinterwimmer (2019) for prominent protagonists in 
several respects. In Section 3.2, we focus on the question of how to identify which time point functions as an anchor. There, we discuss a range of data illustrating interesting problems.

\subsection{Properties indicating the prominence status of a time point and the analysis of FID}

We seek to determine the prominence value of potential anchor times of FID. Therefore, we first need to specify more precisely what it is that makes a time point prominent in general. The properties influencing the prominence value of times are quite varied. Several are already noted in Becker and Egetenmeyer (2018a). Further relevant properties are mentioned in the context of prominence scales concerning individual referents when aspectual factors are taken into account (see Hopper \& Thompson, 1980; Næss, 2007). They are lexical properties of the verb phrase which may be contextually updated. In the following, we synthesize these factors. The properties we discuss are potential "prominence-lending properties" (Himmelmann \& Primus, 2015: 41). Paralleling Hinterwimmer's (2019) account concerning the perspectival center, the properties are divided into local ones and others operating on a macro-level. Both kinds may interact or may possibly be superimposed on one another. As we will see, the two underlying properties yielding prominence in the domain of time are referential precision and structural salience or weight.

The local prominence properties pertain to the sentence-level. They may be grammatical or lexical. The decisive underlying text-referential property is referential precision. A referentially very precise time point or time span may be overtly introduced by means of an adverbial expression. As Becker and Egetenmeyer (2018a: $47 \mathrm{ff}$.) show, a temporal interval introduced by a sentence adverbial tends to be of elevated prominence. However, referential precision can also be reached by means of the verb phrase, either with a specifying adverbial expression or without it. On this level, an important factor is the marking of a verb with a perfective tense or through Aktionsart properties such as telicity and reduced or minimal temporal extension, as found in achievements. In the terms of Hopper and Thompson (1980: 251 f.), the properties of boundedness and punctuality amount to the expression of the "effectiveness with which an action takes place". Apart from telicity in a strict sense, ingressivity attributed to an eventuality may also be relevant for the prominence status of a particular time point. As is well known, grammatical and lexical aspect interact in a clause (see e.g., De Swart, 1998). Therefore, when determining the prominence value of a certain time point, the different contributing factors cannot always be singled out well, and it is important to keep their sum in mind.

The macro-level prominence properties concern discursive chronology, on the one hand, and "tempus relief" in the sense of Weinrich (1982: 168), on the other. The chronological discourse structure allows us to determine the first time point of an episode or sub-episode which has an elevated prominence value. As Becker and Egetenmeyer (2018a: $47 \mathrm{ff}$; 2018b) show, its structural importance may be specified on quantitative grounds, or, more specifically, a first time point is the one 
to which the highest number of other time points is directly or indirectly anchored. "Tempus relief" is described by Weinrich (1982: $168 \mathrm{ff}$.) as the structuring of texts into foreground and background, which in the Romance languages is indicated by tense-aspect forms: perfective tense-aspect forms tend to mark foreground and imperfective forms background eventualities. A further possibility for foregrounding an eventuality and the time point at which it holds true is to mark it as being in progress by means of a progressive form (see Becker \& Egetenmeyer, 2018a: 54). Foregrounded eventualities are expected to be more prominent than backgrounded ones, a mapping which extends to texts with diversified story lines, where eventualities and the associated time points of the main story line are also expected to be more prominent than those pertaining to lower-ranked story lines (see Becker \& Egetenmeyer, 2018a: 53 f.).

In general, the prominence value of a time point is determined relative to the value of the surrounding time points in the same domain (see Egetenmeyer, accepted $b$ and further references therein). The analysis of the prominence value of the temporal anchor of a FID event needs to consider its relationships to two other time points or groups of time points. The first one holds between the anchor and the time point contributed by the FID event itself (see Section 4.1). The second kind of relationship is the one between the anchor time point and further surrounding time points (see Sections 4.2 and 4.3). Up to now, we have spoken of the temporal anchor in an abstract fashion. In the following section, we will explore it more specifically.

\subsection{Determining the anchor time point of FID}

In many examples presented in the recent research literature, the temporal anchor of a FID event is easily determined. An important reason for this is that the examples often consist of only two sentences, where the second is the FID instance and the first introduces a time point which functions as the anchor of the FID. By contrast, original literary examples are not always equally simply structured. Furthermore, as we saw already in Section 2.2, it is easy to construe short examples which do not precisely fit the pattern.

A relatively frequent semantic characteristic is that the FID event may be anchored to a time point introduced by a verb expressing or implying a thought or feeling. Such a verb can function as a trigger for the FID, but the FID can also be realized without one. In [13], the context contains a verb of sentience (scbämte sich, "felt ashamed"). Even though it facilitates the occurrence of the FID, the FID is temporally anchored to a time point introduced by another verb. Thus, [13] exemplifies the issue of intervening sentences between the one introducing the anchor time point and the FID ${ }^{12}$.

12. The purpose of the sentence numberings is to make the discussion easier. We do not use them in other sections to improve readability. 
[13] (1) Im Zimmer machte er kein Licht. (2) Er schämte sich, indes sie aus dem Dunkel hinaufspähte, das Zimmer zu beleuchten, das ihr gehört hatte. (3) Es regnete. (4) Wie viele Stunden hatte sie gewartet? (5) Gewi[ss] stand sie noch immer dort, mit ibrer letzten Hoffnung. (6) Das war nicht auszubalten!

(H. Mann, Der Untertan, 1918: 99)

'(1) He was afraid to turn on the light in the room. (2) While she stood out there in the dark, looking up, he was ashamed to light up the room which had belonged to her. (3) It was raining. (4) How many hours had she been waiting? (5) She was probably still there, waiting with her last hope. (6) This was more than be could stand.'

(H. Mann, The Patrioteer, 1921: 84)

The sentence directly preceding the FID is a description (es regnete, "it rained"). Temporally speaking, it is not relevant for the thought event. Rather, it holds true at the time of the eventuality we are looking for, and it includes the reference time in question (see Kamp \& Rohrer, 1983: 254, whose conception of temporal development in texts we follow here). The sentence before it does not push the narrative time forward either. It expresses the feelings of the protagonist which hold at a time previously introduced into the discourse. Finally, the FID event is temporally anchored to the time interval introduced in the first sentence of the extract, namely, the time point when the character enters the room. Still, the realization of the FID in (4) to (6) ${ }^{13}$ is very readily accessible due to the expression of the protagonist's feelings in sentence (2).

The second interesting case in point is exemplified in [14], which shows a tendency quite different from that of [13]. The example may be considered a borderline case with respect to our account, because the anchor time does not seem to have an elevated prominence value. However, as we are about to see, the FID is licensed through a so-called viewpoint shift.

[14] (1) Dann fing sie an, neugierig unter den Visitenkarten und Briefschaften auf dem Sekretär zu kramen...

(2) Dicht beim Tintenfa[ss] lag das wohlbekannte große Schreibheft mit gepre[ss] tem Umschlag, goldenem Schnitt und verschiedenartigem Papier. (3) Es $m u[s s]$ te noch gestern Abend gebraucht worden sein, und ein Wunder nur, da[ss] Papa es nicht wie gewöbnlich in der Ledermappe und in der besonderen Scbublade dort binten verscblossen batte.

(T. Mann, Buddenbrooks. Zerfall einer Familie, 1963: 137)

'(1) Then she began to rummage curiously among the visiting-cards and letters on the desk. (2) Close by the inkstand lay the well-known large copy-book with the stamped cover, gilt edges, and leaves of various qualities and colo[ø]rs. (3) It must have been used the evening before, and it was strange that Papa had not put it back in its leather portfolio and laid it in its special drawer.'

(T. Mann, Buddenbrooks. The Decline of a Family, 1922: 158)

13. In the English translation, sentence (6) does not maintain the marks of FID from the original German sentence. 
The first sentence of [14] introduces an eventuality in which a human protagonist is involved. The second sentence literally expresses a stative situation concerning a non-human entity, Schreibheft ("notebook"). Therefore, one might expect the anchoring to function in the same way as in the preceding example. In [13], sentences (2) and (3) expressed states and therefore the FID was anchored to a time point introduced in the first sentence. However, this is not the case in [14]. Rather, in [14], the FID is anchored to a time point associated with sentence (2). This is also unexpected as it does not mention any potential conceptualizer, which, however, is necessary for a FID to be realized. Still, the constellation can be argued for as follows. Firstly, sentence (3) expresses a thought concerning the notebook (Scbreibheft) from sentence (2). Secondly, sentence (1) makes reference to (the beginning of) an action, under which the situation in (2) cannot be subsumed. Importantly, the situation in (2) is not asserted for the time introduced in (1) but for a posterior time. And the FID event is anchored to this posterior time. But how can the lack of an explicit reference to a speech or thought event in (2) and to a human protagonist be resolved? Most importantly, how can a conceptualizer, which is necessary to the FID, be retrieved? The answer is that the FID expressed in (3) is licensed by an implicit perception event associated with the second sentence. A necessary concept to resolve this is viewpoint shifting, also sometimes called perspective taking, as described, for instance, in Hinterwimmer (2017). While, in (1), a narrator tells the story, (2) shifts the viewpoint to the character (in Genette's terms, 1980: 190, a "non-focalized narrative" is changed to an "internal focalization"). This means that sentence (2) asserts that the protagonist recognizes the surprising position of the notebook, and on these grounds, she then reflects on it by means of FID in (3). Thus, the anchor time is not merely introduced by a state (with potentially low prominence). Rather, the moment of recognition functions as the anchor time, which has at least an equal prominence value to the time in (1).

To complete the picture, we repeat the following example, already presented in Section 2.2. It pertains to a further group which lacks reference to a speech or thought event and which does not show signs of viewpoint shift to the protagonist.

[15] (1) Bob was sitting next to Anna. (2) How she had looked at him!

(Eckardt, 2014: 48, adapted) ${ }^{14}$

This example does not present the complications discussed above. Sentence (1) directly concerns the protagonist to whom the FID in (2) is attributed. Importantly, in (1), the protagonist is asserted to be in a position where a speech or thought event is not excluded. Apparently, this is enough to license the occurrence of the FID. Without further context, the progressive expresses that an eventuality is ongoing at a certain point in time (see Bertinetto, 1986: 120) ${ }^{15}$. What is important

14. The original in Eckardt (2014: 48) actually contains a non-progressive form in the first sentence (sat). The example is suspected to be less acceptable in that case (see also Egetenmeyer, submitted a).

15. In the example, the time point is underspecified, a frequent phenomenon in natural language. 
for us is that, therefore, the eventuality is asserted to hold true at an identifiable time point. The FID event is anchored to this time point.

A further issue we want to address is the lack of a bounded time point in the sentence preceding the FID. Interestingly, such examples (see [16], taken from Egetenmeyer, accepted a) are presented relatively often in the literature (see e.g., Eckardt, 2014: 88, who presents a rather similar example).

[16] (1) Tom was unhappy. (2) Tomorrow was Christmas and be wouldn't be able to celebrate with bis family.

According to a superficial reading of [16], the state expressed in sentence (1) holds within a temporal interval which is extended, or even unbounded. As we saw in Section 2.2, FID events have a specific temporal extension, namely the location time of the uttering or thinking event. Apparently, this temporal interval is relatively short in comparison to a state like the one seemingly referred to in the first sentence of the example. On these grounds, a viable interpretation would be that the FID event simply takes a subperiod of the interval as anchor. The reference time of the FID event would be underspecified in such cases. Even though this is possible, a resolution process like the following one seems more probable. In [16], the FID content is the reason for Tom's feeling. The two eventualities overlap. They may be described as approximately sharing the initial time point, with the state expressed in (1) still holding after the FID event expressed in (2) is completed. Thus, they determine each other in terms of their temporal properties (see the concept of "cospecification", which Pustejovsky [1991: 422] describes for verb-argument relations). A similar thought with respect to the content specifications of indirect speech verbs and indirect speech can be found in Hunter (2016: 18). However, she goes beyond such an analysis when showing that, in indirect discourse, the relationships of the parenthetical and the embedded clause with respect to the surrounding context may diverge, as "both parts of a discourse parenthetical report can be rhetorically relevant" (Hunter, 2016: 32) ${ }^{16}$.

\section{Analysis of the temporal anchor of FID events}

To verify our hypothesis that the temporal anchor of FID is prominent, and to gain insight into the functioning of the assumed categories, we analyzed a specific data set in depth. It consists of fifty instances of FID. All examples were collected from the research literature. They include both literary examples and examples made up by the scholars concerned. Most of the examples were collected by an assistant who was deliberately given only rather rudimentary instructions in order to limit any

16. The account is interesting in the context of FID, especially due to the insights concerning rhetorical relations. However, we will not go into further detail here, because temporal relations are not a major focus in Hunter (2016). In addition, our account focuses on cases without explicit verbs of speech or thought, which, by contrast, are a central part of the problem treated in the cited paper. 
possible bias. Because the examples are used to show many different characteristics of FID in the research literature, they represent a broad range of cases. The examples were generally not altered. However, those originating from literary works were counterchecked and, where necessary, further context from the original was added, to allow for precise insights on the macro-structural level.

The following sections cover the characteristics of the temporal anchor of FID that may contribute to an increased prominence value. First, we investigate the rhetorical relationship between the sentences introducing the temporal anchor and the FID event (Section 4.1). We then compare the temporal anchor to other surrounding time points, focusing on local (Section 4.2) and macro-structural information (Section 4.3) as described in Section 3.1. As we will see, nearly all examples show prominence effects on at least one level. However, in Section 4.4, we discuss a possible counter-example. The discussion shows that our approach is not easily falsified.

\subsection{Rhetorical relations between the clause contributing the anchor time point and the FID event}

The first important relationship is the one holding between the clause introducing the anchor time point and the FID event. Their relative prominence value can be determined on the grounds of rhetorical relations, which are the semantic or conceptual connections holding between adjacent sentences (see e.g., Asher \& Lascarides, 2003). Asher and Lascarides (2003) and others distinguish between coordinating and subordinating rhetorical relations. The distinction allows us to determine a hierarchical structuring (see Asher \& Lascarides, 2003). Examples of coordinating relations are PARALLEL, NARRATION and CONTRAST, while ELABORATION and EXPLANATION are examples of subordinating relations (see Jasinskaja \& Karagjosova, forthcoming). The two groups differ in the way in which content is added to a preceding clause, which is realized either on the same plane (coordination) or in a subordinating manner. The hierarchical structuring is also used to determine which propositions are available for a further discourse structural attachment: according to the so-called right frontier constraint, only those propositions are available for attachment which are "on the right" of the discourse structure at a certain point of the discourse, where we may find more than one proposition when they are localized on different hierarchical planes (see Asher \& Lascarides, 2003: 11, with reference to Polanyi, 1988). In the present contribution, the basic distinction between non-subordinating and subordinating relations will suffice. The distinction shares similarities with that between foreground and background (see Weinrich, 1982: $168 \mathrm{ff}$.). Still, the description in terms of rhetorical relations is much more detailed and, not unrelatedly, may sometimes lead to diverging classifications. It thus makes available a refined distinction in terms of prominence relations (see also Jasinskaja et al., 2015: $146 \mathrm{ff}$.).

According to our hypothesis, the clause providing the anchor time point should be more prominent than the FID event. In terms of rhetorical relations, this means 
that the FID instance is subordinate to the clause via which the anchor time is introduced. In our data set, 37 of the instances investigated display subordinating relations ( $74 \%$ of the total) as opposed to 13 cases of coordinating relations $(26 \%)$. We ran a simple Chi-squared test in order to determine whether the distribution deviates from an even distribution ${ }^{17}$. It yielded a $p$-value of $p<0.001$. With certain reservations due to the special quality of the data, we rejected the null hypothesis ${ }^{18}$.

The group of cases with subordinating relations comprises 25 ELABORATIONS (67.6\% of the subordination group) and 12 EXPLANATIONS (32.4\%).

The first case in point is the ELABORATION relation.

[17] Un doute singulier me saisit: avais-je aimé réellement Judith?

(Margueritte, L'avril. La confession posthume, 1905: 102; taken from Vetters, 1994:

180, who follows Lips, 1926: 53) ${ }^{19}$

'Doubt came upon me: bad I really loved Judith?'

(Vetters, 1994: 180)

[18] Il annonça sa décision. Il allait se marier.

(Vetters, 1994: 179)

'He announced his decision. He was going to get married.'

(Vetters, 1994: 179)

[19] Elle le regardait de ses grands yeux fixes: pourquoi donc ne mourait-il pas, puisqu'elle ne l'aimait plus, et qu'il gênait tout le monde, maintenant?

(Zola, La bête bumaine, 1984: 302; taken from Landeweerd \& Vet, 1996: 159)

'She observed him with her great staring eyes; why on earth did he not die, since she had ceased to love him, and he was now in the way of everyone?

(Zola, The Monomaniac, 1901: 282) ${ }^{20}$

In [17], the FID expresses what the doubt (doute) is about. This seems to be a productive pattern in the case of subordinating relations. In the example,

17. It would have been preferable to take as a point of comparison the distribution of rhetorical relations in contexts of direct and/or indirect speech. More specifically, these should be the relations holding between a preceding sentence and the one containing the speech verb. However, to our knowledge, this has not been investigated.

18. The relatively small set of data was specifically collected for the analysis by an assistant who received only basic instructions (see Section 4). The null hypothesis was that subordinating and coordinating relations would be evenly distributed. However, the Chi-squared test yielded a $p$-value of $p=0.0006885$. We divided the value by 2 to arrive at the one-sided $p$-value, which supported our expectation of a preference for the subordinating relation.

19. Vetters (1994: 180) deviates from the original and from Lips (1926: 53) by inverting the participle and the adverb (réellement aimé). We adhere to the original.

20. We prefer this translation over the one presented in Landeweerd and Vet (1996: 159), with the exception of the translation of puisque: while the translation by Vizetelly (Zola, 1901: 282) displayed above opts for "since", Landeweerd and Vet (1996: 159) use "for", which fits the FID reading better. 
the preceding clause at least implies a thought event. Example [18] shows that the speech or thought event may also be referred to explicitly. By contrast, [19] exemplifies that the lack of a speech or thought event in the clause introducing the anchor time does not hinder the analysis in terms of rhetorical relations, here another case of ELABORATION ${ }^{21}$.

As said, about one third of the instances with a subordinating rhetorical relation are EXPLANATiOns. This is exemplified in [20], where the FID presents the reason for the eventuality realized according to the preceding clause.

[20] Du coup, Nana perdit la tête, étranglée elle-même par des sanglots nerveux. On abusait d'elle, à la fin! Est-ce que ces histoires la regardaient?

(Zola, Nana, 1880: 256; taken from Vuillaume, 2000: 117)

'As a result, Nana lost her head, trembling with sobs so that she could hardly breathe. She was being abused after all! Did these stories concern her?'

(Our translation) ${ }^{22}$

The data set contains 13 cases of coordinating relations ( $26 \%$ of the data set). Eleven of them are NARRATIONS, while the remaining two are a RESULT and a CONTRAST relation. The following two examples show a NARRATION relation.

[21] She fetched herself a chair. She pitched her easel with her precise old-maidish movements on the edge of the lawn, not too close to Mr. Carmichael, but close enough for his protection. Yes, it must have been precisely here that she bad stood ten years ago. There was the wall; the hedge; the tree.

(Woolf, To the Lighthouse, 1974: 168; taken from Doron, 1991: 52)

[22] She wondered if he was still asleep, how did she even fall asleep and on top of bim?! Was be... shirtless? Ob... he was...

(https://www.fanpop.com/spots/blair-and-chuck/articles/27570/title/reality-perfection-ft-chuck-blair-nate-serena-chapter-3, last accessed 26/11/2019; taken from Maier, 2015: 349)

21. An anonymous reviewer had reservations with respect to this classification. On the one hand, this might be due to traces of causality, which might be interpreted as favoring a classification as an EXPLANATION relation. Interestingly, the causal connotation goes both ways as the protagonist's thoughts might be a reason for the staring, but also what she sees might incentivize her negative thoughts towards the person she is looking at. However, the causality between the two sentences remains vague. On the other hand, there might be arguments for a PARALLEL relation, but the two sentences do not seem to show the necessary independence from each other. Finally, an ELABORATION relation does not pose similar problems and the subsequent context speaks in its favor. The looking event can be understood as part of an "objective" main story line which interacts with prolonged passages presenting the thoughts of the protagonist. At the point within the story of the example, the protagonist's looking is crucial, as she has come to see her husband who has been badly injured in an accident but who remains alive. The FID, by contrast, presents only partly new content in that the preceding passage repeatedly mentions the protagonist's hatred for her husband.

22. Rascoe's (Zola, 1922: 199) translation diverges quite strongly from the original: "Nana scarcely knew what she did, choking as she was with nervous sobs. It was too much! Did all these matters concern her?". 
In [21], the protagonist presents thoughts about her physical position. She realizes them after having placed the easel in the position referred to in the preceding clause. Thus, the thought expressed as FID clearly follows the positioning of the easel. As an anonymous reviewer pointed out, this is underlined by the use of here, which the protagonist can only employ after her arrival at the point in question. Paralleling our discussion above, [22] shows that a NARRATION relation can come about even when the sentence introducing the anchor time point explicitly makes reference to a speech or thought event. In the example, the preceding clause already expresses a thought event. However, the content of the thought differs in the FID. Therefore, the FID event temporally follows the anchor time.

The last example we present in this section contains a RESULT relation (see Kehler, 2000: 193). According to Jasinskaja and Karagjosova (forthcoming), who follow Asher and Lascarides (2003), it is a coordinating relation.

[23] J'ai sorti de ma poche le "compte rendu" que j’avais signé. Elle habitait donc square de l'Alboni. Je connaissais cet endroit pour être souvent descendu à la station de métro toute proche. Aucune importance si le numéro manquait. Avec le nom: Jacqueline Beausergent, je me débrouillerais.

(Modiano, Accident nocturne, 2005: 27; taken from Reboul et al., 2016: 265)

'I took the report I had signed out of my pocket. So she lived on Square de l'Alboni. I knew the area, as I often got off at the metro station close by. It didn't matter that the number was missing. I'd work it out with her name, Jacqueline Beausergent.'

(Modiano, Paris nocturne, 2015: 19) ${ }^{23}$

In [23], the FID in question (Aucune importance..., "It didn't matter...") makes reference to a result following from what is stated in the sentence preceding $\mathrm{it}^{24}$. More specifically, the RESULT relation holds between the state of knowing the place and the assessment that the lack of more precise information is unproblematic ${ }^{25}$. In the passage, the reading of the train of thought comes about easily with the first-person narrator.

As we have seen, the rhetorical relation holding between the clause introducing the anchor time and that of the FID is predominantly of a subordinating type. This speaks in favor of the hypothesis that the anchor time point is prominent. We assume that the subordinating relation is the prototypical case. Therefore, it may

23. We prefer the translation by Weston-Evans (Modiano, 2015) over the one presented in Reboul et al. (2016: 265), even though the FID is translated less literally and therefore may not strike the reader as an equally obvious instance of FID.

24. The second sentence of the example is another instance of FID.

25. An anonymous reviewer suggested that it might also be a CONSEQUENCE relation, which would be subordinating. The two relations share certain characteristics. It seems to us that we should maintain its classification as a RESULT relation because it "entail[s] the truth of the contents associated with their terms" (Asher \& Vieu, 2005: 598), which is the case in the example. By contrast, the CONSEQUENCE relation is not veridical, i.e., it does not entail that the content of both components of the relation must be true (see Asher \& Lascarides, 2003: 169). Still, according to Asher and Vieu (2005), in certain specific contexts, a RESULT relation may be subordinating. However, when applied to this example, their four tests (Asher \& Vieu, 2005: 599-604) all favor a coordinating relation. 
be expected to occur relatively frequently in the made-up examples. This is indeed the case: among the non-literary examples, there are only $14.3 \%$ of coordinating relations, while there are $30.6 \%$ among the literary examples ${ }^{26}$.

\subsection{Local prominence properties of the anchor time}

In Section 3.1, we discussed the ingredients which determine the prominence status of a time point on the local level. We departed from the concept that prominence is a relational property. The prominence value is determined with respect to the value of the surrounding time points. What typically endorses a prominent reading are lexical and grammatical properties which enable the relevant elements of a clause to make reference to an ideally precise and bounded temporal interval of little extension. Explicitness may be contributed by adverbial expressions. With regard to eventualities, temporal extension is, to some degree, determined by the Aktionsart of a verb phrase. In certain languages including the Romance languages, boundedness may also be contributed by grammatical aspect.

The data also support our claim on this level. In sum, 38 cases (76\%) show an elevated or equal prominence value, which also has at least some prominence to it, or where a non-prominent value is overwritten. More specifically, 9 instances clearly show an elevated prominence value on the local level (18\%), 25 are of at least equal prominence (50\%), and in 4 instances $(8 \%)$ a low value is cancelled out. By contrast, there are only 12 cases (24\%) where the preceding time point has a low prominence value at the local level. Again, we ran a basic Chi-squared test, comparing the distribution among the group which showed prominence and the one without local prominence with an even distribution (null hypothesis). It yielded a $p$-value of $p<0.001^{27}$. Despite maintaining our reservations (see Sections 4 and 4.1), we therefore rejected the null hypothesis.

The following two examples show cases of elevated prominence value.

[24] Puis, en revenant vers la gare [...], il songea, il s'étonna de sa démarche. Avait-il donc résolu de tuer Roubaud, puisqu'il disposait déjà de sa femme et de son argent?

(Zola, La bête bumaine, 1984: 305; taken from Landeweerd \& Vet, 1996: 158)

'Then, on his way back towards the station [...], he thought the matter over, and felt astonished at what he had just done. Had he then resolved to kill Roubaud, since be was disposing of his wife and money?

(Zola, The Monomaniac, 1901: 285) ${ }^{28}$

26. The divergence is not significant. The Fisher test leaves us with a $p$-value of $p=0.303>0.05$. This might have to do with the restricted data set.

27. We did not consider the cases where the low prominence value was overwritten and tested only the groups with at least equal prominence and without prominence. The Chi-squared test yielded a $p$-value of $p=0.00118$. Again, due to our expectation that a prominent anchor would be preferred, we divided the value by 2 in order to arrive at the one-sided $p$-value.

28. Again, we present the translation by Vizetelly (Zola, 1901: 285) and not the one from Landeweerd and Vet (1996: 158). The reason is the more direct translation of the sentence containing the anchor time. 
[25] Du coup, Nana perdit la tête, étranglée elle-même par des sanglots nerveux. On abusait d'elle, à la fin! Est-ce que ces histoires la regardaient?

(Zola, Nana, 1880: 256; taken from Vuillaume, 2000: 117)

'As a result, Nana lost her head, trembling with sobs so that she could hardly breathe. She was being abused after all! Did these stories concern ber?

(Our translation)

In [24], the anchor time point is the reference time which is introduced via the location time corresponding to s'étonna ("felt astonished"). Superficially, we see an ingressive verb marked with the passé simple, which is preceded by another verb with the passé simple form. We may deduce, therefore, that the reference time is at least of equal prominence. However, if we have a closer look at the temporal structure contributed by the lexical constellation, we find that the anchor time is rendered prominent by means of what we may call a climax. This can be argued for as follows. The first verb in the sentence preceding the FID makes reference to an extended (though delimited) temporal interval, while the second one expresses very little temporal extension. The two pertain to the same lexical field and the sequence makes their direct semantic relationship clear. Thus, the clause containing the second verb (s'étonna, "felt astonished") not only marks the endpoint of the first one with songea ("thought"), but also presents a consequence. Therefore, it is semantically heavy. Additionally, compared to the preceding eventuality, its extension is lower. Altogether, the reference time which it introduces is rendered prominent.

In [25] (see also Section 4.1), the anchor time is marked as prominent through the combination of the tense-aspect form (the passé simple in perdit, "lost") and the adverbial expression $d u$ coup ("therefore"). More specifically, the temporal update is combined with the expression of a consequence, i.e., an argumentative update, which together elevate the prominence of the proposition in question (see Egetenmeyer, submitted b) ${ }^{29}$. Lexically as well, there is clear potential for the favoring of prominence. The verb expresses a change of mental state. Therefore, the event is a good candidate to stand out in the narrative. Temporal structurally, the asserted time has little extension and high explicitness, which also contributes to the potential of a high prominence value.

In the following, we present two variants of example [25] where we have changed specific properties to determine their effect on the prominence status more clearly.

29. Prominence in the context of argumentation is discussed in Anscombre and Ducrot (1997) under the term of force. 
[26.a] Les yeux de Muffat s'emplirent de larmes. [...] Au même moment, Nana perdit la tête, étranglée elle-même par des sanglots nerveux. On abusait d'elle, à la fin! Est-ce que ces histoires la regardaient?

(Zola, Nana, 1880: 256, adapted)

'Muffat's eyes filled with tears. At the same time, Nana lost her head, trembling with sobs so that she could hardly breathe. She was being abused after all! Did these stories concern her?

(Our translation)

[26.b] Nana pleurait toute la journée, étranglée elle-même par des sanglots nerveux. On abusait d'elle, à la fin! Est-ce que ces histoires la regardaient?

(Zola, Nana, 1880: 256, adapted)

'Nana cried the whole day, trembling with sobs so that she could hardly breathe. She was being abused after all! Did these stories concern her?'

(Our translation)

In variant [26.a], we have added a sentence from the original text and changed the adverbial expression ${ }^{30}$. This yields a PARALLEL relation, which we use to discard the consequential reading. In [26.b], we have changed the verb in the sentence preceding the FID to the atelic verb pleurer ("to cry"). With the aim of excluding a monofocalized progressive reading (see Bertinetto, 1986: 164), which would elevate the prominence value, we combine it with an extended adverbial expression. The adaptions have the following effects. In variant [26.a], the prominence value is reduced to the default equal value. There is a punctual verb with perfective tense-aspect marking, but no additional prominence cues. Still, it appears to be felicitous. Variant [26.b], by contrast, is linguistically a little less natural. Here, we intend to reduce the prominence value of the anchor time even further. The imparfait verb without a monofocalized reading should yield a state in temporal structural terms (see Kamp \& Rohrer, 1983). However, FID events strictly prefer non-extended anchor times. Still, despite being odd, the example does not seem to be completely excluded. We hypothesize that the clash is resolved in one of the two following manners. First, if the original reading of an EXPLANATION relation is maintained, the FID event is anchored to the left boundary of the eventuality as specified by the adverbial or a pre-phase of it. That means that the thought is realized at the beginning of the day in question, which leads to the crying. The second possibility is a re-interpretation as an ELABORATION relation. Then the thought event is understood as occurring iteratively throughout the day. Importantly, both possibilities again involve a prominence cline in terms of rhetorical relations (see Section 4.1).

With regard to equal prominence, a very typical constellation involves the anchor time being introduced via a verb expressing a telic event.

30. However, we left out two further short sentences which intervene in the original text. 
[27] Un doute singulier me saisit: avais-je aimé réellement Judith?

(Margueritte, L'avril. La confession postbume, 1905: 102; taken from Vetters, 1994: 180)

'Doubt came upon me: had I really loved Judith?'

(Vetters, 1994: 180)

In [29], the anchor time is introduced via a stative expression (en voulait $\grave{a}$, "was angry at") ${ }^{31}$. The reader might infer that the sentence makes reference to an

31. An anonymous reviewer underlined the role of the reason for the psychological state of the individual referent in question, namely, the loss of the Spanish museum (musée espagnol), which is referred back to with an indirect anaphor in the FID through the word peintre ("painter"). Accordingly, the psychological state might be reinterpreted as ingressive. 
utterance event, but, on the one hand, it is not clear what exactly would be uttered (see Hinterwimmer, 2017, who relates this characteristic to viewpoint shifts), and, on the other hand, this reading is not unequivocal as the sentence might also be understood differently, activating common ground information. Additionally, the time at which the event holds true is underspecified. Thus, the temporal anchor is not marked locally as being prominent.

Additionally, there are four cases with characteristics that need a proper discussion. We classify them as cases where the low prominence value is overwritten. They share the property with the group presented above that the clause which contributes the anchor time does not feature indicators of positive prominence. In contrast to what we have seen above, however, this clause makes explicit reference to a speech or thought event. Due to this lexical specificity, the same strict criteria should not be applied to this group, because, importantly, they do not share the same complication as a diverging interpretation is thus excluded. An example is [30].

[30] Elle se demandait s'il n'y aurait pas eu moyen, par d'autres combinaisons du hasard, de rencontrer un autre homme; et elle cherchait à imaginer quels eussent été ces événements non survenus, cette vie différente, ce mari qu'elle ne connaissait pas. Tous, en effet, ne ressemblaient pas à celui-là. Il aurait pu être beau, spirituel, distingué, attirant $[\ldots]$.

(Flaubert, Madame Bovary, 1951: 365; taken from Weinrich, 1982: 802)

'She would wonder whether there might not have been some way, through some different set of circumstances, for her to have met a different man; and she tried to imagine what they might have been, those circumstances which had not arisen, that different life, that unknown husband. For indeed not all busbands were like this one. He might have been handsome, witty, distinguished, attractive [...].'

(Flaubert, Madame Bovary: Provincial Manners, 2004: 41)

In [30], the anchor time is introduced via a non-telic (though possibly ingressive) expression (cherchait à imaginer, "tried to imagine") and the example lacks any further indicators of prominence. Additionally, it should be mentioned that the passage is intended to have a habitual reading, which may also be understood as contributing to a low prominence value (see Becker \& Egetenmeyer, 2018b). However, as noted above, the verb phrase makes explicit reference to a thought event. Due to the explicitness on the content level, the FID event is readily anchored to the anchor time. Therefore, we deduce that the use of verbs of speech or thought in the sentence contributing the anchor time may overwrite the lack of temporal precision ${ }^{32}$.

32. It may be added that the data set also contains two cases where the expression of speech or thought co-occurs with indicators of a positive prominence value. These are counted as part of the group with at least equal prominence value. 


\subsection{Macro-level prominence properties of the anchor time}

In addition to the local prominence properties, we investigated global prominence properties. As discussed in Section 3.1, two main factors are relevant in this respect: the chronological structure and the "tempus relief" (see Weinrich, 1982: 168). The chronology is important in relation to the first time point of an episode. The "tempus relief" concerns the structuring of a text passage into foreground and background. One possible means of highlighting an eventuality as part of the foreground is, for instance, via a progressive form (see Becker \& Egetenmeyer, 2018a: 54; 2018b). Another relevant grounding factor may be the partitioning into story lines.

Again, the data set clearly speaks in favor of our account. Concerning the macro level, 39 cases are plausibly ${ }^{33}$ at least of equal prominence value (78\%), 8 cases show clear marks of an elevated prominence value (16\%) and 31 may be classified as equally prominent (62\%). By contrast, only 9 instances involve indicators of a low prominence value (18\%). Finally, there are two examples with somewhat ambiguous properties (4\%). The simple Chi-squared test we ran to compare the distribution among the groups with and without prominence as opposed to an even distribution (null hypothesis) again yielded a $p$-value of $p<0.001^{34}$. For this third constellation too, we rejected the null hypothesis despite the reservations we have regarding the data (see Sections 4 and 4.1).

In example [31], the prominence value of the anchor time is high because it is the first-mentioned time point of a new sub-episode (see Becker \& Egetenmeyer, 2018a: $47 \mathrm{ff}$.). The original quote in Banfield (1982: 219) actually lacks the necessary amount of context for this to become apparent ${ }^{35}$, which is often the case in the literature. However, by adding further material from the preceding context we are able to underline the positional role of the event introducing the anchor time as being the first time point of an episode.

33. In the literary examples, we added further context wherever possible. By contrast, in the examples that were made up by fellow linguists, there is not always sufficient linguistic material available to clearly determine all relevant macro-level properties. However, many cases may plausibly be classified as being intended to pertain to the foreground, because the lack of context often leaves no possibility of specifying otherwise. Still, this cannot be fully generalized, as we also encountered two examples where it is not the case.

34. We did not include the two cases of doubt. The Chi-squared test yielded a $p$-value of $p=0.0000149$. As our expectation was that a prominent anchor would be preferred, we divided the value by 2 again to arrive at the one-sided $p$-value.

35. Banfield's (1982: 219) example starts only with Il s'y montra gai, which she translates as "He seemed in high spirits about it". We disagree with her interpretation of $y$. An anonymous reviewer underlined the anaphoric reference of $y$ to pique-nique. We agree and assume that the translator, Robert Baldick, opted for on the day for stylistic reasons, as it is sufficiently precise but more elegant than a repetition of (during the) picnic. Anaphoric there and then, by contrast, do not seem to be free of ambiguities. 
[31] Frédéric passa la sienne trois jours après. Avant de partir en vacances, il eut l'idée d'un pique-nique, pour clore les réunions du samedi.

Il s'y montra gai. Mme Arnoux était maintenant près de sa mère, à Chartres. Mais il la retrouverait bientôt, et finirait par être son amant.

(Flaubert, L'éducation sentimentale: bistoire d'un jeune homme, 1870: 152; partly taken from Banfield, 1982: 219)

'Frédéric sustained his own thesis three days later. Before leaving for his holidays, he hit on the idea of a picnic, to bring the Saturday gatherings to a close.

He was in high spirits on the day. Madame Arnoux was now ${ }^{36}$ away at Chartres with her mother. But they would come together again soon, and he would be her lover in the end.' (Flaubert, Sentimental Education, 2004: 95 f., adapted)

In [31], the protagonist develops the idea of a picnic which he then hosts. There is, thus, a temporal gap between the two situations, the idea and the day of the picnic. The disruption in the story line also correlates with the formal means of a paragraph break. We can determine the second situation, the one we are most interested in, as a new (sub-)episode on the grounds that the time, the location and the persons involved change (see Van Dijk, 1982: 177). Thus, the anchor time point of the FID, which is the reference time introduced via montra ("showed"), is the first-mentioned time point of a new sub-episode and has, therefore, an elevated prominence value (again, see Becker \& Egetenmeyer, 2018a: 47 ff.).

The eventualities via which the anchor time is introduced are often part of the foreground (see below). Still, this does not per se yield a high prominence value. Prominence is only elevated if the eventuality in question, which pertains to the foreground, is preceded by a backgrounded passage (see [32]), or if, as already noted, the eventuality is specifically marked as being foregrounded.

[32] Je pensai à mon père, que j’avais peu connu, ayant dix ans lorsqu'il mourut; je revoyais mal son visage, dont la sévérité me faisait peur [...]. [...]

Puis je revis mon enfance, mon temps d'examens à Paris, mon affection bizarre pour Judith, mes efforts et la position acquise pour lui plaire, puis son refus [...]. [...] Un doute singulier me saisit: avais-je aimé réellement Judith?

(Margueritte, L'avril. La confession posthume, 1905: 102; partly taken from Vetters, 1994: 180)

'I thought of my father, whom I had hardly known, as I was ten years old when he died; I didn't recall his face well, the severity of which frightened me. [...]

Then I relived my childhood, the time of my exams in Paris, my strange affection for Judith, my efforts and the position acquired to please her, then her rejection. [...]

Doubt came upon me: had I really loved Judith?"

(The translation is ours except for the last two clauses which are taken from Vetters, 1994: 180)

36. We have added now to the translation to induce the FID reading more clearly. 
Example [32] has already been discussed, but without the additional preceding material. With it, the overall structure can be determined. In terms of rhetorical relations, there are three summarizing statements, namely those which contain the verbs pensai ("thought"), revis ("relived") and saisit ("took hold"), which are then elaborated on (see Section 4.1 for subordinating rhetorical relations). The verbs of these summarizing statements are all marked by the passé simple, thus indicating that they belong to the foreground (see Weinrich, 1982: 168). The passage shows strict thematic coherence. Therefore, the eventuality via which the anchor time is introduced (saisit, "took hold") is not described as the first time point of a new episode. The passage is also coherent concerning the persons involved (the main person is clearly the first-person narrator), and therefore does not show signs of a diversified story line either. Still, and importantly, saisit ("took hold") introduces a time point where the relief switch from the background to the foreground takes place. Therefore, its prominence value is elevated with respect to the preceding context.

In the data set, the anchor time is frequently introduced by an eventuality in the foreground, where the grounding does not increase its prominence value further. This is the case in 36 instances $(72 \%)^{37}$.

[33] She fetched herself a chair. She pitched her easel with her precise old-maidish movements on the edge of the lawn, not too close to Mr. Carmichael, but close enough for his protection. Yes, it must have been precisely here that she bad stood ten years ago. There was the wall; the hedge; the tree.

(Woolf, To the Lighthouse, 1974: 168; taken from Doron, 1991: 52)

The passage in [33], already mentioned in Section 4.1, is about an important character in the book. The NARRATION relation holding between the first two sentences of the extract makes it perfectly clear that the eventuality introducing the anchor time (pitched) is part of the foreground.

In literary examples, the classification of foreground material is generally not problematic. Where necessary, additional preceding material can be taken into account. However, the data set also contains non-literary examples, where further linguistic material may simply be non-existent. The question is how to deal with such examples (see, e.g., example [34]). We argue that despite the reduced preceding context, for many of them being part of the foreground is plausible, partly because of an eventive preceding clause and partly also due to the lack of alternative interpretations available in the restricted context (see also footnote 33 ). Therefore, we also classify such cases as being of equal prominence in this respect (see [34]).

37. Among the 36 instances are 4 cases where the anchor time is also the first time point (yielding an elevated global prominence value), and one where the global prominence value is reduced as the clause concerned, even though it is part of the foreground, appears in a subordinating rhetorical relation to the one which precedes it. This leaves the 31 instances of a "truly" equal prominence value referred to at the beginning of the section. 
[34] Mary smiled. Tomorrow she would reveal her true identity at the press conference.

(Hinterwimmer, 2019: 80)

The final group we want to discuss is the one where the anchor time of FID does not show a positive prominence value on the macro-level. This is the case when the eventuality introducing the anchor time pertains to the background, e.g., as part of a description. Our data set contains eight instances of this kind (see [35]).

[35] Charlot said quickly, "I couldn't turn him out without so much as a piece of bread. That wouldn't have been human. I let him out the back way". Thérèse somb[er]ly looked away from him, watching the wet world outside. They could hear the rain coming up in gusts against the house, beating against the windows and dripping from the eaves. It wasn't a night for any buman being to be abroad in, and he thought, how be must bate Chavel.

(Greene, The Tenth Man, 1985: 110; partly taken from Juillard, 2000: 84)

In [35], the verb in the first sentence following the direct speech (looked away) introduces a reference time. The state expressed in the following sentence (could hear) temporally includes this reference time and does not advance the story further (see, for this kind of analysis, Kamp \& Rohrer, 1983: 254). Still, the FID event is introduced relative to the state. An important argument favoring this analysis is that the thought is realized not by Thérèse but by Charlot, who is only reintroduced in the stative sentence which expresses that both can hear the rain (see Hinterwimmer, 2019, and Section 2.1 ${ }^{38}$. Additionally, it is reasonable to assume that the ability to hear the rain implies the act of listening to the rain, which has a more or less specific beginning set after the looking away of Thérèse. The FID event may be taken to stand in a temporally close relationship to this beginning. What is of most interest to us, however, is that the FID is anchored to a time point which is part of a description (background). Thus, an anchor time may also be introduced via a non-foregrounded eventuality and lack macro-level prominence. However, as we have seen, this is not overly frequent.

\subsection{The case of counter-examples}

To find out whether there are any examples contradicting our hypothesis, we crossreferenced our results concerning the anchor's rhetorical relation with the FID and its local and global-level prominence value. More precisely, we checked our data set for clauses contributing anchor time points holding a coordinating rhetorical relation with the FID and which also did not show any other sign of an elevated prominence value. Such cases are very rare. There are four instances with a coordinating relation

38. In fact, according to Hinterwimmer (2019: 86), Charlot should be available as a perspectival center already in the sentence making reference to Thérèse $(T$. [...] looked away $[\ldots])$ because he is the discourse topic. Still, without the clause referring to the state of being able to hear the rain, the example becomes slightly less acceptable. 
which additionally show a low prominence value on one of the two levels but an equal prominence value on the other level. Together, they make up $38.5 \%$ of the cases with coordinating rhetorical relations and $10 \%$ of the whole data set. However, there is only one example where both levels are exempt from positive prominence indicators. This one true counterexample only represents $2 \%$ of the data analyzed.

The example was already presented in Section 4.1 (see also the footnotes there for discussion).

[36] J'ai sorti de ma poche le "compte rendu" que j’avais signé. Elle habitait donc square de l'Alboni. Je connaissais cet endroit pour être souvent descendu à la station de métro toute proche. Aucune importance si le numéro manquait. Avec le nom: Jacqueline Beausergent, je me débrouillerais.

(Modiano, Accident nocturne, 2005: 27; taken from Reboul et al., 2016: 265)

'I took the report I had signed out of my pocket. So she lived on Square de l'Alboni. I knew the area, as I often got off at the metro station close by. It didn't matter that the number was missing. I'd work it out with her name, Jacqueline Beausergent.'

(Modiano, Paris nocturne, 2015: 19)

Despite the anchor time being classified as lacking an elevated prominence value regarding all three relational properties we consider in the present contribution, the reading of the example as an instance of FID is unimpeachable. Interestingly, however, it combines at least two properties which already make it special from the outset. On the one hand, there is a first-person narrator (see e.g., Vetters [1994: $192 \mathrm{f}$.] for a discussion of this property as a possible problem and, additionally, Eckardt [2014: 51] for the possibility of referential identity of narrator and protagonist), and on the other hand, the FID occurs in an embedded passage which already shows signs of thought representation before the FID in question. First of all, there is donc ("so") (see e.g., Eckardt, 2014: 114 ff.). Second, apart from the verb of knowing itself (connaissais, "knew"), the non-distal demonstrative cet ("this") might be interpreted as a hint towards a focalized perspective. Thus, as the example is quite a unique case, we may expect that such true counter-examples to our theory are indeed not frequent.

\section{Conclusion: prominence in temporal and individual reference in FID}

In this contribution, we presented evidence for the elevated prominence value of the anchor time of FID events. We discussed three main categories: the rhetorical relation between the clause introducing the anchor time and the FID event, and the properties of the anchor time on a local level and on a macro-level. The last two paralleled the categories applied in Hinterwimmer (2019) (see below). Our hypothesis was favored in all three respects: we found many more subordinating (74\%) than coordinating relations $(26 \%)$ in our data. On the local level, the majority of instances 
were at least of equal prominence (76\%). Also, concerning the macro-level, most cases could plausibly be determined as showing at least some prominence (78\%). Our data set only contains one clear counterexample, which, however, is quite a unique case in other regards as well (see Section 4.4). Therefore, we conclude that there is indeed a strong tendency towards a prominent anchor time of FID.

On these grounds, we want to briefly compare the properties of the anchor time point with those of the perspectival center presented in Hinterwimmer (2019). This will enable us to answer the question of whether the anchor time point parallels the prominence value of the perspectival center in FID. With regard to the prominence domain, the set of available protagonists is typically quite restricted in narratives, which is less the case with regard to time points. While there are often only a few protagonists available in a narrative, there may be close to an infinite number of time points. Still, due to computational restrictions, only recently introduced time points are expected to play a role in this respect.

The rhetorical relation between the preceding clause and the FID does not play much of a role in the analysis of the perspectival center (see Hinterwimmer, 2019) ${ }^{39}$. By contrast, on the local level, both the analysis of the perspectival center and the anchor time are based on grammatical and semantic features indicating an elevated prominence value. Finally, the macro-level is also at play in a parallel manner in both respects. Thus, even though the precise properties are clearly different in nature, prominence can be shown to be relevant in very much a parallel fashion.

The present article contributes to the understanding of FID by focusing on a determining factor of the temporal relations involved, namely, the status of the temporal anchor. The detailed description of the prominence value of the anchor time amounts to an advancement in the research on prominence in language. An important further contribution lies in the comparison between the domains of times and of individuals. With this article as background, future work should broaden the database. A collection of FID instances that is independent of the research literature might lead to different frequency distributions and perhaps also to additional classification challenges. A further step is to substantiate the findings with experimental evidence (see Egetenmeyer, submitted a).

\section{References}

Abrusán, M. 2020. The Spectrum of Perspective Shift: Protagonist Projection vs. Free Indirect Discourse. Linguistics and Philosophy. Available online: https://link.springer. com/article/10.1007/s10988-020-09300-z.

Aissen, J. 2003. Differential Object Marking: Iconicity vs. Economy. Natural Language and Linguistic Theory 21 (3): 435-483.

39. An anonymous reviewer suggested, however, that this could be beneficial. 
Altshuler, D.G. 2010. Temporal Interpretation in Narrative Discourse and Event Internal Reference. PhD dissertation. New Brunswick: Rutgers University.

Anand, P. \& Toosarvandani, M. 2018a. Unifying the Canonical, Historical, and Playby-Play Present. In R. Truswell, C. Cummins, C. Heycock, B. Rabern \& H. Rohde (eds.), Proceedings of Sinn und Bedeutung 21. Vol. 1: 19-34. Available online: https:// semanticsarchive.net/Archive/DRjNjViN/AnandToosarvandani.pdf.

Anand, P. \& Toosarvandani, M. 2018b. No Explanation for the Historical Present: Temporal Sequencing and Discourse. In U. Sauerland \& S. Solt (eds.), Proceedings of Sinn und Bedeutung 22. ZAS Papers in Linguistics 60. Berlin: ZAS. Vol. 1: 73-90. Available online: https://semanticsarchive.net/Archive/GE4MWViN/AnandToosarvandani.pdf.

Anderson, C.J. 2019. Tomorrow isn't Always a Day Away. In M.T. Espinal, E. Castroviejo, M. Leonetti, L. McNally \& C. Real-Puigdollers (eds.), Proceedings of Sinn und Bedeutung 23. Bellaterra (Cerdanyola del Vallès): Universitat Autònoma de Barcelona. Vol. 1: 37-56. Available online: https://ojs.ub.uni-konstanz.de/sub/index.php/sub/ article/view/493.

Anscombre, J.-C. \& Ducrot, O. 1997. L'argumentation dans la langue. Sprimont: P. Mardaga [3rd ed.].

Asher, N. \& Lascarides, A. 2003. Logics of Conversation. Cambridge - New York Melbourne: Cambridge University Press.

Asher, N. \& Vieu, L. 2005. Subordinating and Coordinating Discourse Relations. Lingua 115 (4): 591-610.

BANFIELD, A. 1982. Unspeakable Sentences: Narration and Representation in the Language of Fiction. Boston: Routledge.

Becker, M. \& Egetenmeyer, J. 2018a. A Prominence-Based Account of Temporal Discourse Structure. Lingua 214: 28-58.

Becker, M. \& Egetenmeyer, J. 2018b. Accounting for Prominence in Temporal Discourse Structure. Plenary talk at the "Klausurtagung of the SFB 1252", 11-12 October 2018, Gummersbach.

Becker, M., Egetenmeyer, J. \& Hinterwimmer, S. accepted. Perspective in German and French: Divergences in Formal Marking and Temporal Anchoring. To appear in Zeitschrift für Literaturwissenschaft und Linguistik (LiLi) 2/2021.

Bertinetto, P.M. 1986. Tempo, aspetto e azione nel verbo italiano. Il sistema dell'indicativo. Florence: Accademia della Crusca.

Bu, J. 2016. A Semantic Study of Tense Backshift and its Literary Effects in FID. Journal of Literary Semantics 45 (1): 49-75.

De Swart, H. 1998. Aspect Shift and Coercion. Natural Language and Linguistic Theory 16 (2): 347-385.

Doron, E. 1991. Point of View as a Factor of Content. In S.K. Moore \& A.Z. Wyner (eds.), Proceedings of the 1st Semantics and Linguistic Theory Conference - SALT 1. Washington: Linguistic Society of America (LSA): 51-64. Available online: http:// journals.linguisticsociety.org/proceedings/index.php/SALT/article/view/3240.

Dowty, D. 1991. Thematic Proto-Roles and Argument Selection. Language 67 (3): 547-619. 
ECKARDT, R. 2014. The Semantics of Free Indirect Discourse. How Texts Allow Us to Mind-Read and Eavesdrop. Leiden - Boston: Brill.

Egetenmeyer, J. 2020. Temporal Prominence Demotion in Updating Imparfait Uses in "L'Étranger". In E. Corre, D.-T. Do-Hurinville \& H.-L. Dao (eds.), The Expression of Tense, Aspect, Modality and Evidentiality in Albert Camus's "L'Étranger" and Its Translations / "L'Étranger" de Camus et ses traductions: questions de temps, d'aspect, de modalité et d'évidentialité (TAME). An Empirical Study / Étude empirique. Lingvisticx Investigationes Supplementa 35. Amsterdam - Philadelphia: J. Benjamins: 118-142.

Egetenmeyer, J. accepted a. Temporal Relations of Free Indirect Discourse Events. Linguistics 59 (4).

Egetenmeyer, J. accepted b. Time Updating Uses of the French Imparfait Extending across Genres. To appear in the series "Cahiers Chronos" (Brill-Rodopi).

Egetenmeyer, J. submitted a. Experimental Evidence for the Elevated Prominence Value of the Anchor Time of French Free Indirect Discourse.

Egetenmeyer, J. submitted b. Textual Development beyond Temporality and Interactions of the Adversative Connector "pero" with the Indefinido.

EhrLich, S. 1990. Point of View. A Linguistic Analysis of Literary Style. London - New York: Routledge.

Genette, G. 1980. Narrative Discourse. An Essay in Method. Ithaca: Cornell University Press.

Giorgi, A. 2015. Free Indirect Discourse and the Syntax of the Left Periphery. In J. Guéron (ed.), Sentence and Discourse. Oxford: Oxford University Press: 232-255.

Himmelmann, N.P. \& Primus, B. 2015. Prominence beyond Prosody - A First Approximation. In A. De Dominicis (ed.), "pS-prominenceS”: Prominences in Linguistics. Proceedings of the International Conference. Viterbo: DISUCOM Press: 38-58. Available online: https:// ifl.phil-fak.uni-koeln.de/sites/linguistik/Personen/ASW/Himmelmann/Publikationen/2011-2015/himmelmann_primus_2015_on_prominence_pS-prominenceS.pdf.

Hinterwimmer, S. 2017. Two Kinds of Perspective Taking in Narrative Texts. In D. Burgdorf, J. Collard, S. Maspong \& B. Stefánsdóttir (eds.), Proceedings of the 27th Semantics and Linguistic Theory Conference - SALT 27. Washington: Linguistic Society of America (LSA): 282-301. Available online: http://journals.linguisticsociety. org/proceedings/index.php/SALT/article/view/27.282.

Hinterwimmer, S. 2018. Der Brenner und die Perspektive: Zum Gebrauch von Demonstrativpronomen in den Brenner-Romanen von Wolf Haas. In M. GENÇ \& C. HamanN (eds.), Kriminographien. Formenspiele und Medialität kriminalliterarischer Schreibweisen. Würzburg: Königshausen \& Neumann: 123-142.

Hinterwimmer, S. 2019. Prominent Protagonists. Journal of Pragmatics 154: 79-91.

Holton, R. 1997. Some Telling Examples: A Reply to Tsohatzidis. Journal of Pragmatics 28 (5): 625-628.

Hopper, P.J. \& Thompson, S.A. 1980. Transitivity in Grammar and Discourse. Language 56 (2): 251-299.

Hunter, J. 2016. Reports in Discourse. Dialogue and Discourse 7 (4): 1-35. Available online: https://journals.uic.edu/ojs/index.php/dad/article/view/10681. 
Jasinskaja, K., Chiriacescu, S., Donazzan, M., Heusinger, K. von \& Hinterwimmer, S. 2015. Prominence in Discourse. In A. DE Dominicis (ed.), " $p S$-prominenceS": Prominences in Linguistics. Proceedings of the International Conference. Viterbo: DISUCOM Press: 134-153. Available online: https://ifl.phil-fak.uni-koeln.de/sites/dslc/martafiles/ Jasinskaja_Chiriacescuetal2015-Prominence-Discourse.pdf.

Jasinskaja, K. \& Karagjosova, E. forthcoming. Rhetorical Relations. In D. GutzmanN, L. Matthewson, C. Meier, H. Rullmann, T. E. Zimmerman (eds.), The Wiley Blackwell Companion to Semantics. Oxford: Wiley-Blackwell.

Juillard, M. 2000. Les Huns sont-ils entrés à cheval dans la bibliothèque? Ou les libertés du style indirect libre. In S. Mellet \& M. Vuillaume (eds.), Le style indirect libre et ses contextes. Cahiers Chronos 5. Amsterdam - Atlanta: Rodopi: 71-90.

Kamp, H. \& Reyle, U. 1993. From Discourse to Logic. Introduction to Modeltheoretic Semantics of Natural Language, Formal Logic and Discourse Representation Theory. Part 2. Dordrecht - Boston - London: Kluwer Academic Publishers.

Kamp, H. \& Rohrer, C. 1983. Tense in Texts. In R. Bäuerle, C. Schwarze \& A. von Stechow (eds.), Meaning, Use, and Interpretation of Language. Berlin - New York: De Gruyter: 250-269.

Kamp, H., Van Genabith, J. \& Reyle, U. 2011. Discourse Representation Theory. In D.M. Gabbay \& F. Guenthner (eds.), Handbook of Philosophical Logic. Dordrecht: Springer. Vol. 15: 125-394 [2nd ed.].

Kaplan, D. 1989. Demonstratives: An Essay on the Semantics, Logic, Metaphysics, and Epistemology of Demonstratives and Other Indexicals. In J. Almog, J. Perry \& H.K. WettsteIn (eds.), Themes from Kaplan. Oxford: Oxford University Press: 481-564.

Kehler, A. 2000. Resolving Temporal Relations Using Tense Meaning and Discourse Interpretation. In M. Faller, S. Kaufmann \& M. Pauly (eds.), Formalizing the Dynamics of Information. Stanford: CSLI Publications: 189-205.

KLEIN, W. 1994. Time in Language. London - New York: Routledge.

KöDER, F., Maier, E. \& Hendriks, P. 2015. Perspective Shift Increases Processing Effort of Pronouns: A Comparison between Direct and Indirect Speech. Language, Cognition and Neuroscience 30 (8): 940-946.

LANDEWEerd, R. \& Vet, C. 1996. Tense in (Free) Indirect Discourse in French. In T. Janssen \& W. VAn DER WurfF (eds.), Reported Speech. Forms and Functions of the Verb. Amsterdam - Philadelphia: J. Benjamins: 141-164.

LIPS, M. 1926. Le style indirect libre. Paris: Payot.

Lo Cascio, V. 2002. Temporal Dimension in Free Indirect Speech. In G.L. Beccaria \& C. Marello (eds.), La parola al testo: scritti per Bice Mortara Garavelli. Alessandria: Edizioni dell'Orso. Vol. 1: 205-220.

MAIER, E. 2015. Quotation and Unquotation in Free Indirect Discourse. Mind and Language 30 (3): 345-373.

MaIER, E. 2017. The Pragmatics of Attraction: Explaining Unquotation in Direct and Free Indirect Discourse. In P. SAKA \& M. Johnson (eds.), The Semantics and Pragmatics of Quotation. Perspectives in Pragmatics, Philosophy and Psychology 15. Cham: Springer: 259-280. 
Næss, A. 2007. Prototypical Transitivity. Typological Studies in Language 72. Amsterdam Philadelphia: J. Benjamins.

Polany, L. 1988. A Formal Model of the Structure of Discourse. Journal of Pragmatics 12 (5-6): 601-638.

Primus, B. 2006. Hierarchy Mismatches and the Dimensions of Role Semantics. In I. Bornkessel, M. Schlesewsky \& B. Comrie (eds.), Semantic Role Universals and Argument Linking. Theoretical, Typological and Psycholinguistic Perspectives. Berlin New York: De Gruyter: 53-88.

Pustejovsky, J. 1991. The Generative Lexicon. Computational Linguistics 17 (4): 409-441.

Reboul, A., Delfitto, D. \& Fiorin, G. 2016. The Semantic Properties of Free Indirect Discourse. Annual Review of Linguistics 2: 255-271.

Schlenker, P. 2004. Context of Thought and Context of Utterance: A Note on Free Indirect Discourse and the Historical Present. Mind and Language 19 (3): 279-304.

Sharvit, Y. 2008. The Puzzle of Free Indirect Discourse. Linguistics and Philosophy 31 (3): 353-395.

VAn Dijk, T.A. 1982. Episodes as Units of Discourse Analysis. In D. TAnnen (ed.), Analyzing Discourse: Text and Talk. Georgetown University Roundtable on Languages and Linguistics 32. Washington: Georgetown University Press: 177-195.

Vetters, C. 1994. Free Indirect Speech in French. In C. Vet \& C. Vetters (eds.), Tense and Aspects in Discourse. Trends in Linguistics. Studies and Monographs [TiLSM] 75. Berlin - New York: Mouton de Gruyter: 179-226.

Vuillaume, M. 2000. La signalisation du style indirect libre. In S. Mellet \& M. Vuillaume (eds.), Le style indirect libre et ses contextes. Cahiers Chronos 5. Amsterdam - Atlanta: Rodopi: 107-130.

WeInRICH, H. 1982. Textgrammatik der französischen Sprache. Stuttgart: E. Klett.

\section{Corpus data}

Flaubert, G. 1870. L'éducation sentimentale: bistoire d'un jeune homme. Paris: M. Lévy frères.

Flaubert, G. 1951. Madame Bovary. Paris: Gallimard.

Flaubert, G. 2004. Madame Bovary: Provincial Manners. Translated by M. Mauldon. Oxford: Oxford University Press.

Flaubert, G. 2004 [1964]. Sentimental Education. Translated by R. Baldick. London New York: Penguin Books.

Greene, G. 1985. The Tenth Man. Harmondsworth: Penguin Books.

ManN, H. 1918. Der Untertan. Leipzig: K. Wolff.

Mann, H. 1921. The Patrioteer. Translated by E. Boyd. New York: Harcourt, Brace and Company.

Mann, T. 1922. Buddenbrooks. The Decline of a Family. Translated by H.T. Lowe-Porter. London: M. Secker.

Mann, T. 1963. Buddenbrooks. Verfall einer Familie. Berlin - Frankfurt am Main: S. Fischer. 
Margueritte, P. 1905. L'avril. La confession posthume. Paris: A. Fayard.

Modiano, P. 2005. Accident nocturne. Paris: Gallimard.

Modiano, P. 2015. Paris Nocturne. Translated by P. Weston-Evans. New Haven: Yale University Press.

Wharton, E. 1997. Twilight Sleep. New York: Simon \& Schuster - Scribner.

Woolf, V. 1974. To the Lighthouse. London: Hogarth Press.

Zola, É. 1880. Nana. Paris: G. Charpentier.

ZolA, É. 1901. The Monomaniac [La bête humaine]. Translated by E.A. VizeTELLY. London: Hutchinson.

ZolA, É. 1922. Nana. Translated by B. Rascoe. New York: A.A. Knopf.

ZoLA, É. 1984. La bête bumaine. Paris: Librairie générale française. 